\title{
Aplicação do desdobramento da função qualidade no desenvolvimento de produtos orgânicos
}

\author{
Jaqueline de Fátima Cardoso \\ Universidade Federal de Santa Catarina - UFSC \\ jaquelinecardoso@yahoo.com.br \\ Nelson Casarotto Filho \\ Universidade Federal de Santa Catarina - UFSC \\ casarotto@deps.ufsc.br \\ Paulo Augusto Cauchick Miguel \\ Universidade Federal de Santa Catarina - UFSC \\ cauchick@deps.ufsc.br
}

\section{RESUMO}

A aplicação do Desdobramento da Função Qualidade (QFD - Quality Function Deployment) no desenvolvimento de produtos alimentares é divulgada em diferentes estudos na literatura. No entanto, o método QFD foi concebido originalmente para outros setores industriais e, para que sua aplicação seja eficaz no setor de alimentos, é necessário fazer algumas adaptações. Nesse contexto, o presente trabalho visa propor uma aplicação do QFD no desenvolvimento de produtos orgânicos. A agricultura orgânica é um sistema de produção que visa à qualidade de vida para quem produz e para quem consome os alimentos, havendo uma crescente procura por esse tipo de produto. Em função de que ainda esse tipo de aplicação do QFD não está empiricamente consolidado na literatura, esta proposta é de natureza exploratória, que gerou uma proposta para aplicação do QFD no desenvolvimento de produtos orgânicos. O modelo conceitual é composto por quatro matrizes e, para apresentação da proposta, foi desenvolvida uma geleia de frutas orgânica. A principal adaptação é na primeira matriz, com a inclusão dos principais atores da cadeia produtiva. Os resultados apontaram a viabilidade do modelo quanto a sua adequação para produtos alimentares. Observou-se que os ingredientes alimentares possuem variação natural na sua composição. Além disso, as muitas interações entre os ingredientes, a influência dos processos produtivos sobre as propriedades funcionais do produto e a influência da cadeia produtiva sobre os ingredientes, fazem com que o desenvolvimento de produtos alimentares tenha variáveis diferentes das de um produto não alimentar.

Palavras-chave: Desdobramento da Função Qualidade, QFD, Desenvolvimento de produtos, Produtos orgânicos.

\begin{abstract}
The application of Quality Function Deployment (QFD) to develop food products is disclosed in different studies in the literature. However, the QFD method is designed for other industrial sectors. Thus, to ensure effective implementation in the food sector, it is necessary to make some adjustments. In this context, this paper aims to propose an application of QFD in the development of organic products. Organic agriculture is a production system that aims at achieving quality of life for those who produce and for those who consume. There is a growing demand for this type of product. Because of that, since QFD application for this type of product is not empirically consolidated in the literature, this proposal is of exploratory nature, which generated a proposal for applying QFD in the development of organic products. The conceptual model consists of four matrices. The application is illustrated through the development of an organic fruit jelly. The main adaptation is the first matrix to consider the inclusion of the major actors in the production supply chain. The results indicate the feasibility of the model with a view to their suitability for food. It was observed that food ingredients have a natural variation in composition. Moreover, the many interactions among the ingredients of the production processes and the influence on the functional properties of the product and the production chain of the ingredients causes the development of food products has different variables of a non-food product.
\end{abstract}

Keywords: Quality Function Deployment, QFD, Product development, Organic products. 


\section{Introdução}

Na década de 1960 as empresas no Japão apresentavam forte crescimento, particularmente o setor industrial automotivo que realizava constantes alterações nos modelos existentes e lançamentos de novos produtos (CARNEVALLI et al., 2004). Isso gerou necessidade de um método que garantisse a qualidade do produto desde a fase do projeto. Segundo Akao (1996), pesquisas foram realizadas para atender a essa necessidade, surgindo assim o método denominado Quality Function Deployment (QFD). O propósito do QFD é traduzir os requisitos de qualidade dos clientes em atributos de um produto, mas também pode ser utilizado para desenvolver serviços (CARNEVALLI; CAUCHICK MIGUEL, 2007). Sua aplicação melhora a confiabilidade do produto, reduz o tempo de projeto (DEVADASAN et al., 2006) e aumenta a satisfação dos clientes (LAGER, 2005; CARNEVALLI et al., 2008).

Diante dos benefícios de sua aplicação, o método foi adotado em outros países, tendo sido introduzido nos EUA e na Europa na década de 1980. No Brasil, foi introduzido somente na década de 1990; as empresas iniciaram a utilização do QFD traduzindo o termo para o português como Desdobramento da Função Qualidade (CARNEVALLI et al., 2004). Na ocasião, o método foi introduzido em uma empresa de alimentos e embalagens (Sadia S.A.). Há relatos de aplicações de QFD no país nesses setores desde 1995 (CHENG, 2003). No entanto, não foram identificadas publicações do uso do QFD no desenvolvimento de alimentos orgânicos que é um nicho de mercado no setor de alimentos.

A produção e o mercado de alimentos orgânicos vêm se expandindo desde os anos 90, tanto no contexto internacional quanto no Brasil (GUIVANT, 2003). A procura por alimentos orgânicos tem-se tornando expressiva em todo o mundo devido à conscientização da população sobre os riscos para a saúde decorrentes da presença de resíduos químicos nos alimentos (ARBOS, 2010). Além disso, o sistema de produção orgânico visa à produção ecologicamente sustentável, economicamente viável e socialmente justa, capaz de integrar o homem ao meio ambiente (SANTOS; MONTEIRO, 2004). Os autores citados afirmam ainda que a adoção de sistema de produção orgânico vem crescendo, tanto em área cultivada como em número de produtores e mercado consumidor, embora ainda represente uma parcela pequena da agricultura. $\mathrm{O}$ crescimento da agricultura orgânica se deve ao fato de a agricultura convencional basear-se na utilização intensiva de produtos químicos, fazendo com que os consumidores vejam nesse sistema de produção uma possibilidade de risco à saúde e ao meio ambiente (SANTOS; MONTEIRO, 2004). A agricultura orgânica é um sistema de produção que visa à qualidade de vida para quem produz e para quem consome os alimentos, e em virtude dessa demanda, o mercado de produtos orgânicos e as projeções futuras apontam para um crescimento ainda maior desse segmento (SANTOS; MONTEIRO, 2004).

Diante das variadas opções de alimentos, os produtores buscam diferenciar a oferta para conquistar os consumidores. Para isso, o QFD é um método que pode auxiliar nesse intento no sentido de captar a voz do cliente e transformá-la em características da qualidade do produto. Frente ao exposto, o presente trabalho visa fazer uma proposição da aplicação do QFD no desenvolvimento de produtos orgânicos. Para a execução da proposta é demonstrado o desenvolvimento de uma geleia de frutas orgânica. Na seqüência, são apresentados os procedimentos metodológicos para a condução do presente trabalho. As seções seguintes tratam de definições a cerca do QFD, bem como da utilização QFD no desenvolvimento de produtos alimentares. Após, é apresentada a proposta de aplicação do QFD no desenvolvimento de produtos orgânicos, seguida pelas conclusões.

\section{Procedimentos metodológicos}

Os procedimentos metodológicos compreendem a execução de 3 etapas. A etapa 1 compreendeu um levantamento bibliográfico a fim de selecionar publicações relevantes sobre o tema, particularmente artigos específicos relacionados a utilização do QFD no desenvolvimento de produtos alimentares orgânicos. A busca em periódicos foi feita nas bases de dados Scopus, ISI-Web of Science, Science Direct e Emerald, tendo como foco publicações nos últimos 10 anos (a partir de 2002), utilizando o termo "quality function deployment" combinado com "agroecologic* farming*"; "agroecologic* product*"; "agricultur* product*";"food product*"; agricultur*; e farming. A base de dados Scielo foi consultada, utilizando os termos: quality function deployment, QFD; desdobramento da função qualidade, sem limite de data. Estas bases de dados são as mais representativas na área. No total foram identificados 37 artigos. Após a leitura dos resumos dos mesmos restaram 13 artigos associados ao tema principal. O critério de seleção dos trabalhos foi tratar do desenvolvimento de produtos alimentares utilizando o QFD, além de apresentar estudos teóricos sobre o QFD no tema em questão. Outros trabalhos foram levantados a partir das referências dos artigos selecionados; para isso, utilizou-se o Google acadêmico.

A etapa 2 consistiu no desenvolvimento de uma proposta de aplicação do QFD e definição do modelo conceitual adequado a esta aplicação. A partir da análise das publicações analisadas na etapa anterior, principalmente o trabalho de Benner et al. (2003a) para o desenvolvimento de produtos alimentares utilizando o QFD, uma proposta de aplicação do QFD foi concebida para o desenvolvimento de produtos orgânicos. 
A referida proposta foi utilizada no desenvolvimento de uma geleia de frutas orgânica. A escolha do modelo de Benner et al. (2003a) justifica-se pelo fato de este ter realizado estudos focados na utilização do QFD no desenvolvimento de produtos alimentares, levantando as dificuldades encontradas. Dessa forma, o autor formalizou adequações do QFD especificamente para utilização em produtos alimentares.

A etapa 3 compreendeu o desenvolvimento da proposta com base no QFD. A aplicação do QFD iniciou com o levantamento das qualidades exigidas junto a quatro consumidores de produtos orgânicos por meio de questionário composto por duas questões abertas, uma relacionada ao produto geleia e outra relacionada à embalagem. A partir das qualidades exigidas extraídas das respostas do questionário, foi elaborado um diagrama de árvore em dois níveis (Quadro 2) a fim de detalhar as qualidades exigidas. Tais qualidades foram avaliadas pelos mesmos consumidores que atribuíram grau de importância de 1 a 5, sendo 1 menos importante e 5 mais importante. Em seguida, foram extraídas as características da qualidade a partir das qualidades exigidas - para isso foram definidos os elementos da qualidade (propriedades físicas, propriedades químicas, sabor, responsabilidade socioambiental, peso e aparência) e elaborado um diagrama de árvore a fím de agrupar as características da qualidade. Com base nos dados anteriores foi construída a primeira matriz de um modelo conceitual, relacionando os elementos da cadeia produtiva com as qualidades exigidas - e indicando o grau de influência de cada ator (pela atribuição de 9 para relação "forte", 3 para "fraca" e em branco para relação inexistente). $\mathrm{Na}$ seqüência, foram construídas as outras matrizes (qualidades exigidas versus características da qualidade; processo produtivo versus características da qualidade; e relação entre as matérias-primas com as características da qualidade). Para estas matrizes 2, 3 e 4 utilizou-se a escala de 9 (relação "forte"), 3 ("moderada"), 1 ("fraca") e inexistente (em branco, equivalente a zero).

Além dos consumidores, foram consultados especialistas da área a fim de coletar informações sobre o processo de elaboração de geleia de frutas e a formação da cadeia produtiva.

\section{Desdobramento da Função Qualidade (QFD - Quality Function Deployment)}

Cheng e Melo Filho (2007, p. 44) conceituam o QFD como "uma forma de comunicar sistematicamente a informação relacionada com a qualidade e de explicar ordenadamente o trabalho relacionado com a obtenção da qualidade, visa alcançar a qualidade durante o desenvolvimento de produto". Para alcançar o objetivo proposto, o QFD utiliza matrizes a fim de promover o desdobramento das qualidades exigidas pelo cliente. Existem duas linhas teóricas para aplicação do método. A primeira é denominada QFD das quatro ênfases (AKAO, 1990), cujas diversas matrizes são elaboradas com ênfase na qualidade, tecnologia, confiabilidade e custos. A outra linha é chamada de modelo das quatro fases (HAUSER; CLAUSING, 1988) trata-se de um modelo simplificado em que são elaboradas quatro matrizes, sendo uma para cada fase: a casa da qualidade, o planejamento dos componentes, o planejamento do processo e o planejamento da produção.

Durante o detalhamento do projeto do produto e processo deve-se utilizar o Modelo Conceitual do QFD. Cheng e Melo Filho (2007, p. 177) definem um modelo conceitual como "um conjunto formado por tabelas e matrizes de um determinado projeto de desenvolvimento, cujas matrizes são sequenciadas em uma relação de efeito-e-causa". Na concepção dos autores, é um caminho por onde o desenvolvimento do projeto deve percorrer a fim de alcançar as metas estabelecidas, sendo o efeito final atender às necessidades do cliente, e, a causa o que deveria ser feito para isso.

A utilização do QFD apresenta benefícios e dificuldades. O estudo de Carnevalli e Cauchick Miguel (2007) aponta benefícios tangíveis, tais como: melhoria da confiabilidade, redução do número de alteração do projeto, diminuição do tempo de projeto e de seus custos, redução de reclamações e aumento da receita. Já os benefícios intangíveis, segundo os autores citados, consistem em ser um método flexível, melhorar a comunicação, auxiliar na tomada de decisão e definir prioridade, aumentar e preservar o conhecimento da empresa, bem como a satisfação dos clientes.

Quanto às dificuldades, Carnevalli e Cauchick Miguel (2007) destacam as seguintes: interpretar o que o cliente deseja; definir as correlações entre qualidade exigida e características da qualidade; definir a qualidade projetada devido à ambigüidade da qualidade exigida e características da qualidade; dificuldade de se trabalhar em equipe; e falta de conhecimento no uso do método. Tais dificuldades têm desmotivado o uso do referido método e os autores propõem uma forma de reduzi-las. As dificuldades levantadas bem como a proposta para reduzi-las podem ser complementadas com os estudos de Benner et al. (2003a; 2003b), especificamente no que diz respeito a produtos alimentares, conforme apresentado na próxima seção.

\section{QFD no desenvolvimento de produtos alimentares}

O método QFD pode ser utilizado no desenvolvimento de diferentes tipos de produtos (BENNER et al., 2003b). Cauchick Miguel (2005) realizou um estudo a 
fim de identificar as melhores práticas no desenvolvimento de produtos utilizando o QFD em sete empresas que operam no Brasil. Observa-se no referido estudo que a aplicação do QFD no setor de alimentos é um caso que faz parte das melhores práticas no país.

Por outro lado, Benner et al. (2003b) questiona se o QFD pode ser utilizado na sua totalidade no desenvolvimento de produtos alimentares, tendo em vista que o método foi desenvolvido para outros setores industriais. Apesar de o QFD ter sido utilizado na indústria alimentar desde 1987, os exemplos publicados são relativamente limitados (BENNER et al., 2003b; HOFMEISTER, 1991). Benner et al. (2003b) colocam que as publicações sobre o QFD no desenvolvimento de produtos alimentares apresentam informações generalizadas e o foco fica na primeira matriz, a da qualidade (qualidade exigida $\mathrm{x}$ características da qualidade). Os autores acrescentam ainda que, após uma análise aprofundada dos exemplos publicados, torna-se claro que a informação não é tão útil como parecia à primeira vista. Para os autores, especialmente com relação ao modelo de quatro fases, as aplicações são muito limitadas, sendo que algumas publicações mencionam a abordagem das quatro fases, mas a grande maioria realmente não vai além da primeira matriz.

Nas conclusões sobre as publicações pesquisadas, Benner et al. (2003b) destacam que o QFD é mais indicado para melhoramento de produtos alimentares já existentes e não para desenvolver novos produtos. Ressalta-se também que uma desvantagem importante do método QFD é que pode ser difícil usar o modelo das quatro fases para a melhoria de produtos alimentares. Tal desvantagem acontece devido à complexidade desses produtos, as muitas interações entre os ingredientes e a influência do processo produtivo sobre as propriedades funcionais do produto. Portanto, para Benner et al. (2003b) isso resulta no fato de que não é possível dar valores-alvo precisos para os requisitos do produto. Outro ponto importante, levantado pelos autores, diz que os ingredientes alimentares também possuem uma variação natural na sua composição e isso implica no fato de ingredientes alimentares terem um desvio padrão maior em comparação com o desvio padrão de peças utilizadas em outros setores industriais.

No entanto, Benner et al. (2003b) afirmam que a matriz da qualidade é muito útil para obter uma visão das informações necessárias com a finalidade de melhorar e desenvolver um produto. Todavia, para os autores, combinando suas experiências usando o QFD com os estudos apresentados por outros pesquisadores, o método tal como é utilizado em outros setores industriais não pode ser aplicado no setor de alimentos sem os devidos ajustes. Nos produtos alimentares, a qualidade final não dependente somente da qualidade dos ingredientes, mas também tem forte dependência dos processos que são aplicados aos ingredientes pelos intervenientes na cadeia produtiva. Diante disso, Benner et al. (2003b) propõem que, para a utilização do QFD no desenvolvimento de produtos alimentares, é muito importante que simplificações sejam feitas para o produto, suas características e interações, a fim de manter as matrizes manejáveis. Essas simplificações têm de ser sustentadas com base no conhecimento de pesquisa e desenvolvimento (P\&D) e dos atores de toda a cadeia produtiva. Outro ajuste ao método QFD, para torná-lo aplicável para alimentos, é que os valores-alvo têm que ser acrescentados de intervalos-alvo, devido ao fato de que os ingredientes são muitas vezes ainda materiais fisiologicamente ativos que, portanto, estão sujeitos a alterações.

Diferentes propostas de modificação do QFD foram feitas de modo a aplicá-lo para o desenvolvimento de produtos alimentares. Hofmeister (1991) propôs o QFD Food Industry Roadmap, em que dois caminhos alternativos são definidos a partir da "voz do cliente", para todo processo de desenvolvimento de novos produtos: o desenvolvimento da embalagem e do alimento. Modificações da primeira matriz, de planejamento de produto, são também encontradas na literatura (BENNER et al., 2003a; 2005). Bech et al. (1994) dividiram as características de engenharia (hows) em técnicas e sensoriais. Enquanto isso, Holmen e Kristensen (1996) dividem os atributos dos clientes em necessidades do usuário intermediário e as necessidades do usuário final.

Tendo em vista os benefícios do QFD e apesar das dificuldades apresentadas por Benner et al. (2003b), o método vem sendo aplicado no desenvolvimento de produtos alimentares tais como frutas (MIGUEL et al., 2007); massa (PINTO; PAIVA, 2010; WAISARAYUTT; TUTIYAPAK, 2006); farinha de trigo (KRISTIANTO; AJMAL; SANDHU, 2012); carne (PARK; HAM; LEE, 2012) e bovinos (ROSADO, 2011). O Quadro 1 sintetiza algumas publicações existentes, quanto aos objetivos, métodos adotados, produto e principais resultados desses trabalhos (para maior detalhamento ver Apêndice 1).

Observa-se, a partir dos estudos mostrados no Quadro 1 que o QFD, quando empregado para desenvolver produtos alimentares, utiliza-se de entrevistas e aplicação de questionários junto aos consumidores, e também da opinião de especialistas - nesse caso possibilita levantar inicialmente as qualidades exigidas e depois priorizá-las de acordo com as opiniões dos clientes. Um dos métodos utilizados em conjunto com o QFD é o Analisys of Cross Cultural Consumer Characterization (4Cs). Nesse caso, o QFD visa tipos diferenciados de clientes e, portanto, diferentes qualidades exigidas dentro de grupos distintos. O método 4Cs coloca que, embora os clientes tenham uma mesma idade ou nível de renda, não necessariamente eles têm o mesmo comportamento de compra por causa de diferentes atitudes e consciência de valor. 
Quadro 1 - Utilização do QFD no desenvolvimento de produtos alimentares

\begin{tabular}{|c|c|c|c|c|}
\hline Referência & Objetivo & Método & Produto & Resultados principais \\
\hline Miguel et al. (2007) & $\begin{array}{l}\text { Estabelecer o comportamento } \\
\text { de compra dos consumidores de } \\
\text { abacaxi através do método QFD. }\end{array}$ & $\begin{array}{l}\text { Entrevista com consumidores. } \\
\text { Degustação. }\end{array}$ & Abacaxi & $\begin{array}{l}\text { O método QFD foi eficiente na avaliação } \\
\text { do produto. Identificada insatisfação dos } \\
\text { consumidores em relação à qualidade do produto. }\end{array}$ \\
\hline Pinto; Paiva (2010) & $\begin{array}{l}\text { Desenvolver uma massa } \\
\text { utilizando o QFD. }\end{array}$ & $\begin{array}{l}\text { Entrevistas com consumidores. } \\
\text { Tabela de desdobramento da } \\
\text { qualidade. } \\
\text { Extração das características do } \\
\text { produto final. } \\
\text { Avaliação sensorial do produto. } \\
\text { Definida a qualidade projetada e as } \\
\text { características da matéria-prima. }\end{array}$ & $\begin{array}{l}\text { Massa alimentícia } \\
\text { pronta para o } \\
\text { consumo com } \\
\text { função prebiótica }\end{array}$ & $\begin{array}{l}\text { A construção das matrizes e as discussões inerentes } \\
\text { a esta atividade proporcionaram uma melhor } \\
\text { percepção das relações entre as características } \\
\text { de qualidade do produto final e os parâmetros de } \\
\text { controle da qualidade das matérias-primas. }\end{array}$ \\
\hline $\begin{array}{l}\text { Waisarayutt; Tutiyapak } \\
\text { (2006) }\end{array}$ & $\begin{array}{l}\text { Avaliar o potencial da } \\
\text { utilização de Desdobramento } \\
\text { da Função Qualidade (QFD) no } \\
\text { processo de desenvolvimento } \\
\text { de produto. }\end{array}$ & $\begin{array}{l}\text { Selecionados } 3 \text { tipos de macarrão. } \\
\text { Pesquisa junto a consumidores. } \\
\text { Utiliza a Analysis of Cross Cultural } \\
\text { Consumer Characterization (4Cs). } \\
\text { Análise sensorial. } \\
\text { Elaboradas as matrizes de } \\
\text { planejamento do produto e de } \\
\text { controle de processo. }\end{array}$ & $\begin{array}{l}\text { Macarrão de arroz } \\
\text { instantâneo }\end{array}$ & $\begin{array}{l}\text { A utilização da } 4 \mathrm{Cs} \text { em conjunto com o QFD } \\
\text { possibilitou maior detalhamento das necessidades } \\
\text { dos diferentes tipos de clientes. }\end{array}$ \\
\hline $\begin{array}{l}\text { Kristianto; Ajmal; } \\
\text { Sandhu (2012) }\end{array}$ & $\begin{array}{l}\text { Pesquisar a satisfação do } \\
\text { cliente levando em conta } \\
\text { a estratégia de gestão da } \\
\text { qualidade total aprovada em } \\
\text { uma empresa de moagem de } \\
\text { farinha de trigo. }\end{array}$ & $\begin{array}{l}\text { Pesquisa de satisfação dos clientes. } \\
\text { Avaliação da concorrência. } \\
\text { Elaborada matriz de produção. } \\
\text { Desenvolvimento de um plano de } \\
\text { ação. } \\
\text { Avaliação do QFD. }\end{array}$ & Farinha de trigo & $\begin{array}{l}\text { O método deve ser aplicado nos níveis mais baixos } \\
\text { de operações a fim de incentivar as pessoas a } \\
\text { aplicar o programa de melhoria de qualidade de } \\
\text { forma mais proativa. Isto encurta o ciclo de vida de } \\
\text { análise entre um QFD e outro e a empresa se torna } \\
\text { mais competitiva. }\end{array}$ \\
\hline Park; Ham, Lee (2012) & $\begin{array}{l}\text { Utilizar o QFD para identificar } \\
\text { as necessidades dos clientes } \\
\text { norte-americanos para um } \\
\text { prato popular coreano. }\end{array}$ & $\begin{array}{l}\text { Utilizado QFD das } 4 \text { fases. } \\
\text { Pesquisa com clientes e especialistas. }\end{array}$ & $\begin{array}{l}\text { Bulgogi (carne } \\
\text { bovina) }\end{array}$ & $\begin{array}{l}\text { Empregou o QFD como ferramenta para melhoria } \\
\text { do produto, e centrou-se na primeira matriz (HOQ). } \\
\text { O modelo das quatro fases, implica aplicações } \\
\text { repetidas de HOQ, nas fases de planejamento de } \\
\text { produto e de planejamento da produção, e dessa } \\
\text { forma, poderia sugerir métodos mais sistemáticos } \\
\text { para aumentar o consumo bulgogi no mercado } \\
\text { internacional. }\end{array}$ \\
\hline Rosado (2011) & $\begin{array}{l}\text { Determinar as principais } \\
\text { características de qualidade } \\
\text { exigidas pelos compradores de } \\
\text { touros em termos de produtos e } \\
\text { serviços associados utilizando } \\
\text { o método de desdobramento da } \\
\text { função qualidade. }\end{array}$ & $\begin{array}{l}\text { Aplicação do QFD considerando } \\
\text { produtos e serviços juntos - modelo } \\
\text { proposto por Ribeiro; Echeveste; } \\
\text { Danilevicz (2000). }\end{array}$ & Carne bovina & $\begin{array}{l}\text { A adaptação do QFD para análise combinada } \\
\text { (produto e serviço) interfere nos resultados, } \\
\text { particularmente aqueles relacionados à priorização } \\
\text { de serviços, e pode ser usada para outros estudos } \\
\text { sobre este produto. }\end{array}$ \\
\hline
\end{tabular}

Fonte: Elaborado pelos autores com base na busca e análise da literatura

Novos produtos alimentares muitas vezes não conseguem ter sucesso porque não são projetados de acordo com os desejos dos consumidores ou não são produzidos de forma eficiente (BENNER et al., 2003a). Frequentemente, as informações necessárias para um processo de desenvolvimento de produto eficaz e eficiente não é retransmitida para o ator adequado da cadeia produtiva. Nesse sentido, Benner et al. (2003a; 2005) apresentam um modelo conceitual para reunir e disseminar informações essenciais tendo como foco o desenvolvimento de produtos, considerando a cadeia produtiva. O modelo baseia-se no método QFD no qual foram feitos ajustes a fim de torná-lo aplicável para o desenvolvimento de produtos alimentares. A proposta é denominada Chain Information Model (CIM) e sugere mudanças na primeira matriz, ilustrada na Figura 1.

Benner et al. (2003a; 2003b) afirmam não ser possível definir valores-alvo precisos para os requisitos da qualidade na matriz de planejamento do produto, devido às seguintes razões: (i) a complexa e variada composição de produtos alimentares, (ii) as interações entre muitos ingredientes, por exemplo, reações químicas, e (iii) a influência da cadeia produtiva e dos processos de produção nas propriedades dos produtos. Sendo assim, inicialmente, são incluídos na primeira matriz, denominada de "Matriz de Informação" (Figura 1), todos os atores da cadeia produtiva, ao invés das características da qualidade. Na parte central da matriz são indicadas as relações "forte", "fraca" ou "inexistente", entre as qualidades exigidas e os atores.

Figura 1 - Matriz de informação (BENNER et al., 2003a; 2007)

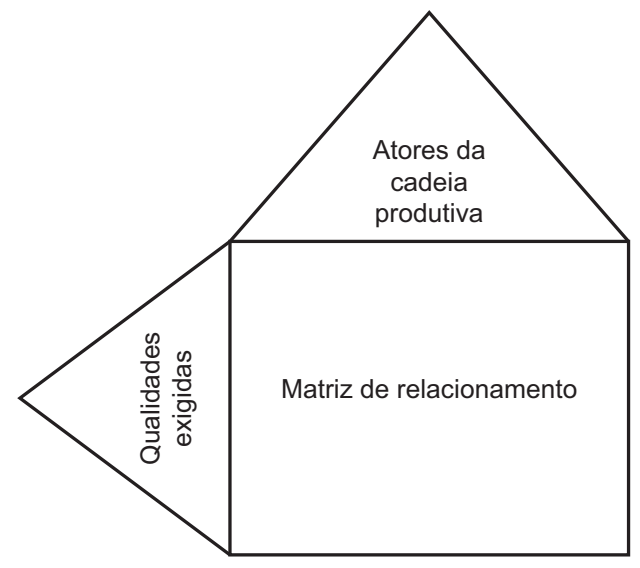

Fonte: Elaborado pelos autores 
O modelo conceitual proposto é composto de três fases: (i) fase de coleta de informações, (ii) fase de processamento de informação, e (iii) fase de divulgação da informação. Na fase de coleta de informações, os dados do consumidor (qualidades exigidas do produto) têm de ser recolhida para garantir o sucesso do procedimento. A cadeia produtiva e os processos também devem ser mapeados para determinar como os atores (ou processos) influenciam as características de qualidade no processo produtivo. Portanto, é possível saber qual a influência de cada membro da cadeia produtiva nas qualidades exigidas pelos consumidores. Para sistematizar a influência dos atores da cadeia produtiva, Benner et al. (2003a) utilizam o Quality Dependence Diagrams (QDD), uma espécie de mapa capaz de fazer as ligações entre as características exigidas e os atores.

Após essa etapa são determinados cenários para a realização do produto pretendido. Esses cenários são formulados na sequência, por meio de uma análise sistemática das opções para cada agente da cadeia de produção. Para cada possível mudança feita por um ator, as consequências para as outras características de qualidade e para os outros atores têm que ser identificadas; árvores de decisão são desenvolvidas para sistematizar essa atividade, bem como metas são estabelecidas para os membros da cadeia produtiva tendo em vista as qualidades exigidas. Determina-se então um cenário preferível, dadas as metas estabelecidas, e distribuem-se as informações necessárias aos atores da cadeia produtiva. A proposta foi construída por meio de aplicação para a produção de uma refeição pronta saudável. Para simplificar, a construção do modelo conceitual focou na melhoria de um produto existente. Nessa aplicação, dois agentes da cadeia foram utilizados, o cultivador de brócolis e o processador de vegetais. Em outro estudo de Benner et al. (2007), a proposta foi utilizada para desenvolver outro produto, um ketchup.

O modelo conceitual proposto por Benner et al. (2003a; 2007), bem como os trabalhos apresentados no Quadro 1 são a base para apresentar uma proposta cujo foco é o desenvolvimento de produtos orgânicos utilizando o QFD.

\section{Proposta de aplicação do QFD no desenvolvimento de produtos orgânicos}

A agricultura orgânica baseia-se na melhoria da fertilidade do solo por um processo biológico natural, pelo uso da matéria orgânica, o que é essencial a saúde das plantas. Esse tipo de agricultura é totalmente contrário à utilização de adubos químicos solúveis e organismos geneticamente modificados. A agricultura orgânica apresenta um conjunto de normas bem definidas para produção e comercialização da produção as quais são determinadas e aceitas internacionalmente e nacionalmente. Atualmente, o nome "agricultura orgânica" é utilizado em países de origem anglosaxã, germânica e latina. Pode ser considerado como sinônimo de agricultura biológica e engloba as práticas agrícolas da agricultura biodinâmica e natural (DAROLT, 2010).

Os produtos originários desse tipo de agricultura são denominados, no Brasil, produtos orgânicos. A partir de 2010, todo produto orgânico brasileiro, exceto aqueles vendidos diretamente pelos agricultores familiares, levam o selo do Sistema Brasileiro de Avaliação da Conformidade Orgânica (SISORG). Para denominação "orgânico" ou "produto orgânico" no rótulo, o produto deve conter, no máximo, 5\% de ingredientes não orgânicos os quais devem ser discriminados (MINISTÉRIO DA AGRICULTURA, PECUÁRIA E ABASTECIMENTO, 2009).

O modelo conceitual proposto é constituído de quatro matrizes, conforme apresentado na Figura 2. O produto escolhido para ser desenvolvido foi uma geleia de frutas orgânica.



Fonte: Elaborado pelos autores

Para a construção da Matriz 1 (Figura 3) foi aplicado um questionário com duas questões abertas junto a consumidores de produtos orgânicos, indagando quais características uma geleia de frutas orgânica deveria ter, em relação ao produto em si e a sua embalagem. A 
Figura 3 - Matriz 1 - qualidades exigidas x cadeia produtiva

\begin{tabular}{|c|c|c|c|c|c|c|c|c|c|c|c|c|}
\hline \multicolumn{2}{|c|}{ Qualidades exigidas } & \multicolumn{7}{|c|}{ Atores da cadeia produtiva } & \multicolumn{4}{|c|}{ Qualidade planejada } \\
\hline Nível primário - Geleia & Nível secundário - Geleia & 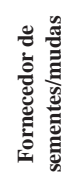 & 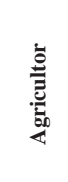 & 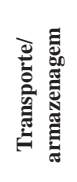 & 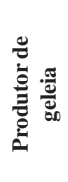 & 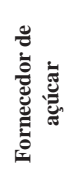 &  &  & 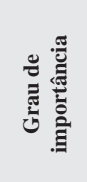 & 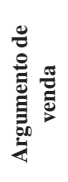 & 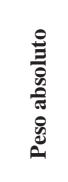 & 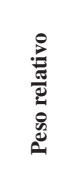 \\
\hline \multirow[t]{4}{*}{ Boa aparência } & Ter cor intensa e viva & & & & 23,9 & & & & 3,5 & 1 & 3,5 & 2,7 \\
\hline & Evidenciar pigmentos naturais da fruta & & & & 34,9 & & & & 4,25 & 1,2 & 5,1 & 3,9 \\
\hline & Ter pedaços da fruta & & & & 46,2 & & & & 4,5 & 1,5 & 6,8 & 5,1 \\
\hline & Não ser uma pasta & & & & 32,8 & & & & 4 & 1,2 & 4,8 & 3,6 \\
\hline \multirow[t]{3}{*}{ Ser saborosa } & Ter pouco açúcar & & & & 27,4 & & & & 4 & 1 & 4,0 & 3,0 \\
\hline & Ter acidez baixa & & & & 20,5 & & & & 3 & 1 & 3,0 & 2,3 \\
\hline & $\begin{array}{l}\text { Ter sabor semelhante ao da fruta de } \\
\text { origem }\end{array}$ & & & 17,1 & 51,3 & & & & 5 & 1,5 & 7,5 & 5,7 \\
\hline \multirow{2}{*}{$\begin{array}{l}\text { Não utilizar produtos } \\
\text { químicos e geneticamente } \\
\text { modificados }\end{array}$} & $\begin{array}{l}\text { Possuir somente produtos naturais sem } \\
\text { conservantes e aditivos químicos }\end{array}$ & 48,7 & 48,7 & 16,2 & 48,7 & 48,7 & & & 4,75 & 1,5 & 7,1 & 5,4 \\
\hline & Utilizar açúcar orgânico & & & & 51,3 & 51,3 & & 5 & 1,5 & 7,5 & 5,7 & \\
\hline Produção familiar & Ser produzida por produtor familiar & & 39,0 & 39,0 & 39,0 & & & & 4,75 & 1,2 & 5,7 & 4,3 \\
\hline $\begin{array}{l}\text { Nível primário - } \\
\text { Embalagem }\end{array}$ & Nível secundário - Embalagem & & & & & & & & & & & \\
\hline $\begin{array}{l}\text { Informações sobre a } \\
\text { procedência do produto }\end{array}$ & $\begin{array}{l}\text { Indicar o produtor e sua relação com } \\
\text { instituições agroecológicas }\end{array}$ & 11,4 & 34,2 & & 34,2 & & & & 5 & 1 & 5,0 & 3,8 \\
\hline \multirow{3}{*}{$\begin{array}{l}\text { Evidenciar a } \\
\text { responsabilidade } \\
\text { socioambiental }\end{array}$} & $\begin{array}{l}\text { Remeter à qualidade de vida do produtor e } \\
\text { do consumidor }\end{array}$ & & 41,0 & & 41,0 & & & & 4 & 1,5 & 6,0 & 4,6 \\
\hline & Indicar a produção agroecológica & 51,3 & 51,3 & & 51,3 & 17,1 & & & 5 & 1,5 & 7,5 & 5,7 \\
\hline & $\begin{array}{l}\text { Apresentar certificação orgânica de acordo } \\
\text { com as normas brasileiras }\end{array}$ & 48,7 & 48,7 & 48,7 & 48,7 & 48,7 & & & 4,75 & 1,5 & 7,1 & 5,4 \\
\hline Possibilitar ver o produto & Ser de vidro & & & & 20,5 & & & & 3 & 1 & 3,0 & 2,3 \\
\hline \multirow{4}{*}{$\begin{array}{l}\text { Permitir o } \\
\text { reaproveitamento }\end{array}$} & Ser utilizada após o consumo & & & & 29,1 & & & & 4,25 & 1 & 4,3 & 3,2 \\
\hline & Possuir refil & & & & 25,6 & & & & 3,75 & 1 & 3,8 & 2,8 \\
\hline & Ter tampa adequada à reutilização & & & & 30,8 & & & & 4,5 & 1 & 4,5 & 3,4 \\
\hline & Ser reciclável & & & & 34,2 & & & & 5 & 1 & 5,0 & 3,8 \\
\hline \multirow[t]{3}{*}{ Tamanho adequado } & Ter de 250 a $300 \mathrm{~g}$ & & & & 22,2 & & & & 3,25 & 1 & 3,3 & 2,5 \\
\hline & Ter de 400 a $500 \mathrm{~g}$ & & & & 17,1 & & & & 2,5 & 1 & 2,5 & 1,9 \\
\hline & $\begin{array}{l}\text { Ter embalagens pequenas (menores de } \\
100 \mathrm{~g} \text { ) }\end{array}$ & & & & 10,3 & & & & 1,5 & 1 & 1,5 & 1,1 \\
\hline \multirow[t]{6}{*}{ Aparência da embalagem } & Ter rótulo de papel reciclável & & & & 30,8 & & & & 4,5 & 1 & 4,5 & 3,4 \\
\hline & Ter rótulo impresso na própria embalagem & & & & 20,5 & & & 3 & 1 & 3,0 & 2,3 & \\
\hline & Ter rótulo colorido & & & & 13,7 & & & & 2 & 1 & 2,0 & 1,5 \\
\hline & Ter rótulo que remeta à natureza & & & & 18,8 & & & & 2,75 & 1 & 2,8 & 2,1 \\
\hline & Ter rótulo simples & & & & 29,1 & & & & 4,25 & 1 & 4,3 & 3,2 \\
\hline & Possuir uma marca & & 10,3 & & 30,8 & & & & 3 & 1,5 & 4,5 & 3,4 \\
\hline \multirow[t]{3}{*}{ Ser fácil de abrir } & Possuir sistema específico para abertura & & & & 15,4 & & & & 2,25 & 1 & 2,3 & 1,7 \\
\hline & Peso absoluto & 160,1 & 273,2 & 121,0 & 900 & 165,8 & 0 & 0 & \multirow{2}{*}{\multicolumn{2}{|c|}{$\begin{array}{l}1.460,1 \\
100 \%\end{array}$}} & 131,6 & 100,0 \\
\hline & Peso relativo & $11 \%$ & $19 \%$ & $8 \%$ & $62 \%$ & $11 \%$ & $0 \%$ & $0 \%$ & & & & \\
\hline
\end{tabular}

Fonte: Elaborado pelos autores

partir das respostas dos indivíduos pesquisados foi elaborado um diagrama de árvore com dois níveis, a fim de detalhar as qualidades exigidas. Na sequência, foram encaminhadas as qualidade exigidas para os consumidores a fim de que eles atribuíssem grau de importância de 1 a 5 (sendo 1 "menos importante" e 5 "mais importante"). A partir de então, foi possível definir a qualidade planejada, incluindo o argumento de vendas, o peso absoluto e relativo.
As relações entre as qualidades exigidas e a cadeia produtiva foram realizadas (escala; $9=$ "forte", $3=$ "fraca" e, em branco, "inexistente"). Observa-se que o agricultor e o produtor, seguidos pelos fornecedores de semente/mudas e açúcar são os atores com maior responsabilidade para atender às qualidades exigidas. $\mathrm{O}$ transportador da matéria-prima também tem sua parcela de responsabilidade, pois os produtos orgânicos não podem ser misturados a produtos não-orgânicos tendo em vista 
o risco de contaminação. Para os atores da cadeia produtiva indicados, devem ser definidas metas a fim de alcançar a qualidade projetada para o produto final.

Tendo em vista as qualidades apontadas pelos consumidores, ou seja, as qualidades exigidas nível primário e secundário, se criou os elementos da qualidade e a partir desses as características da qualidade do produto final (Quadro 2). Nesse momento, a Matriz 2 foi construída. Essa matriz relaciona as qualidades exigidas com as características da qualidade (Figura 4); para isso utilizou-se a escala: 9 = "relação forte", 3 = "relação moderada", 1 = "relação fraca", e em branco, "inexistente" ou zero. Nessa matriz foi projetada a qualidade que a empresa deseja para o produto final com base nas relações estabelecidas.

A Matriz 3 (Figura 5) compreende as características da qualidade e o processo produtivo. Os resultados dessa matriz demonstram que as etapas do processo produtivo

Quadro 2 - Qualidades exigidas pelos consumidores, elementos da qualidade e características da qualidade

\begin{tabular}{|c|c|c|c|}
\hline \multicolumn{2}{|c|}{ Qualidades exigidas } & \multirow{2}{*}{ Elementos da qualidade } & \multirow{2}{*}{ Características da qualidade } \\
\hline Nível primário - Geleia & Nível secundário - Geleia & & \\
\hline \multirow[t]{5}{*}{ Boa aparência } & Ter cor intensa e viva & Propriedades físicas & $\begin{array}{l}\text { Ter pigmentos da fruta } \\
\text { Ter pedaços da fruta }\end{array}$ \\
\hline & Evidenciar pigmentos naturais da fruta & Propriedades físicas & Ter pigmentos da fruta \\
\hline & Ter pedaços da fruta & Propriedades físicas & Ter pedaços da fruta \\
\hline & \multirow[t]{2}{*}{ Não ser uma pasta } & Propriedades físicas & Ter pedaços da fruta \\
\hline & & Propriedades físicas & Ter concentração adequada de pectina (\%) \\
\hline \multirow[t]{4}{*}{ Ser saborosa } & Ter pouco açúcar & Sabor & Ter concentração adequada de açúcar (\%) \\
\hline & \multirow[t]{2}{*}{ Ter acidez baixa } & \multirow[t]{2}{*}{ Sabor } & Ter concentração adequada de açúcar (\%) \\
\hline & & & Ter acidez adequada $(\mathrm{pH})$ \\
\hline & Ter sabor semelhante ao da fruta de origem & Sabor & Ter concentração adequada de açúcar (\%) \\
\hline \multirow[t]{2}{*}{ Não utilizar produtos químicos } & $\begin{array}{l}\text { Possuir somente produtos naturais sem } \\
\text { conservantes e aditivos químicos }\end{array}$ & Propriedades químicas & $\begin{array}{l}\text { Ter no máximo 5\% de ingredientes não } \\
\text { orgânicos }\end{array}$ \\
\hline & Utilizar açúcar orgânico & Propriedades químicas & No máximo $5 \%$ de ingredientes não orgânicos \\
\hline Produção familiar & Ser produzida por produtor familiar & Responsabilidade socioambiental & $\begin{array}{l}\text { Ser proveniente da agricultura familiar } \\
\text { agroecológica }\end{array}$ \\
\hline Nível primário - Embalagem & Nível secundário - Embalagem & & \\
\hline $\begin{array}{l}\text { Informações sobre a procedência } \\
\text { do produto }\end{array}$ & $\begin{array}{l}\text { Indicar o produtor e sua relação com } \\
\text { instituições agroecológicas }\end{array}$ & Responsabilidade socioambiental & $\begin{array}{l}\text { Ser proveniente da agricultura familiar } \\
\text { agroecológica }\end{array}$ \\
\hline \multirow[t]{3}{*}{$\begin{array}{l}\text { Evidenciar a responsabilidade } \\
\text { socioambiental }\end{array}$} & $\begin{array}{l}\text { Remeter à qualidade de vida do produtor e } \\
\text { do consumidor }\end{array}$ & Responsabilidade socioambiental & $\begin{array}{l}\text { Ser proveniente da agricultura familiar } \\
\text { agroecológica }\end{array}$ \\
\hline & Indicar a produção agroecológica & Responsabilidade socioambiental & $\begin{array}{l}\text { Ser proveniente da agricultura familiar } \\
\text { agroecológica }\end{array}$ \\
\hline & $\begin{array}{l}\text { Apresentar certificação orgânica de acordo } \\
\text { com as normas brasileiras }\end{array}$ & Responsabilidade socioambiental & Possuir selo de certificação SISORG \\
\hline Possibilitar ver o produto & Ser de vidro & Propriedades físicas & Ser reciclável e/ou reutilizável \\
\hline \multirow[t]{4}{*}{ Permitir o reaproveitamento } & Ser utilizada após o consumo & $\begin{array}{l}\text { Propriedades físicas } \\
\text { Responsabilidade socioambiental }\end{array}$ & Ser reciclável e/ou reutilizável \\
\hline & Possuir refil & $\begin{array}{l}\text { Propriedades físicas } \\
\text { Responsabilidade socioambiental }\end{array}$ & Ser reciclável e/ou reutilizável \\
\hline & Ter tampa adequada à reutilização & $\begin{array}{l}\text { Propriedades físicas } \\
\text { Responsabilidade socioambiental }\end{array}$ & Ser reciclável e/ou reutilizável \\
\hline & Ser reciclável & $\begin{array}{l}\text { Propriedades físicas } \\
\text { Responsabilidade socioambiental }\end{array}$ & Ser reciclável e/ou reutilizável \\
\hline \multirow[t]{3}{*}{ Tamanho adequado } & Ter de 250 a $300 \mathrm{~g}$ & Peso & Ter embalagem entre 250 e $300 \mathrm{gr}$ \\
\hline & Ter de 400 a $500 \mathrm{~g}$ & Peso & Ter embalagem entre 250 e $300 \mathrm{gr}$ \\
\hline & Ter embalagens pequenas (menores de $100 \mathrm{~g}$ ) & Peso & Ter embalagem entre 250 e $300 \mathrm{gr}$ \\
\hline \multirow[t]{6}{*}{ Aparência da embalagem } & Ter rótulo de papel reciclável & Aparência & Ter rótulo de papel reciclável \\
\hline & Ter rótulo impresso na própria embalagem & Aparência & Ter rótulo impresso na embalagem \\
\hline & Ter rótulo colorido & Aparência & Ter rótulo colorido \\
\hline & Ter rótulo que remeta à natureza & Aparência & Ter rótulo ilustrado \\
\hline & Ter rótulo simples & Aparência & Ter rótulo de papel reciclável \\
\hline & Possuir uma marca & Aparência & Possuir uma marca \\
\hline Ser fácil de abrir & Possuir sistema específico para abertura & Propriedades físicas & Possuir lacre para abertura \\
\hline
\end{tabular}

Fonte: Elaborado pelos autores com base nos dados primários 
Cardoso, J. F.; Casarotto Filho, N.; Miguel, P. A. C. - Aplicação do desdobramento da função qualidade...

Figura 4 - Matriz 2 - qualidades exigidas x características da qualidade

\begin{tabular}{|c|c|c|c|c|c|c|c|c|c|c|c|c|c|c|c|c|c|c|c|c|c|}
\hline \multicolumn{2}{|c|}{ Qualidades exigidas } & \multicolumn{16}{|c|}{ Características da qualidade } & \multicolumn{4}{|c|}{ Qualidade planejada } \\
\hline $\begin{array}{l}\text { Nível primário - } \\
\text { Geleia }\end{array}$ & $\begin{array}{l}\text { Nível secundário - } \\
\text { Geleia }\end{array}$ & 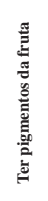 &  &  & 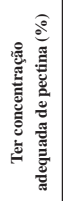 & 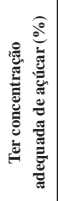 & 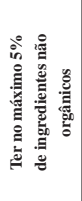 & 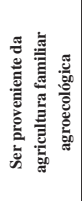 & 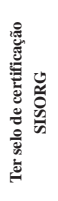 & 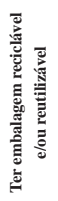 & 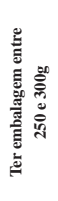 & 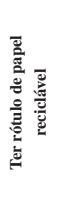 & 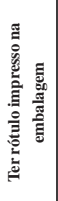 & 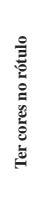 & 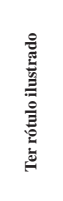 & 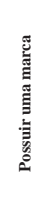 &  & 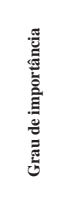 & 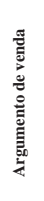 & 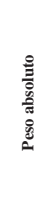 &  \\
\hline \multirow[t]{4}{*}{ Boa aparência } & Ter cor intensa e viva & 8,0 & & & & 23,9 & & & & & & & & & & & & 3,5 & 1 & 3,5 & 2,7 \\
\hline & $\begin{array}{l}\text { Evidenciar pigmentos } \\
\text { naturais da fruta }\end{array}$ & 34,9 & 34,9 & & & & & & & & & & & & & & & 4,25 & 1,2 & 5,1 & 3,9 \\
\hline & Ter pedaços da fruta & 46,2 & 46,2 & & & & & & & & & & & & & & & 4,5 & 1,5 & 6,8 & 5,1 \\
\hline & Não ser uma pasta & 3,6 & 32,8 & & 32,8 & 32,8 & & & & & & & & & & & & 4,5 & 1,5 & 4,8 & 3,6 \\
\hline \multirow[t]{3}{*}{ Ser saborosa } & Ter pouco açúcar & & & 27,4 & & 27,4 & & & & & & & & & & & & 4 & 1 & 4,0 & 3,0 \\
\hline & Ter acidez baixa & & & 20,5 & & 20,5 & & & & & & & & & & & & 3 & 1 & 3,0 & 2,3 \\
\hline & $\begin{array}{l}\text { Ter sabor semelhante } \\
\text { ao da fruta de origem }\end{array}$ & & 17,1 & 5,7 & & 51,3 & & & & & & & & & & & & 5 & 1,5 & 7,5 & 5,7 \\
\hline \multirow[t]{2}{*}{$\begin{array}{l}\text { Não utilizar produtos } \\
\text { quimicos }\end{array}$} & $\begin{array}{l}\text { Possuir somente } \\
\text { produtos naturais } \\
\text { sem conservantes e } \\
\text { aditivos quimicos }\end{array}$ & & & & 48,7 & & 48,7 & 16,2 & 48,7 & & & & & & & & & 4,75 & 1,5 & 7,1 & 5,4 \\
\hline & $\begin{array}{l}\text { Utilizar açúcar } \\
\text { orgânico }\end{array}$ & & & & & & 51,3 & 51,3 & 51,3 & & & & & & & & & 5 & 1,5 & 7,5 & 5,7 \\
\hline Produção familiar & $\begin{array}{l}\text { Ser produzida por } \\
\text { produto familiar }\end{array}$ & & & & & & & 39,0 & & & & & & & & & & 4,75 & 1,2 & 5,7 & 4,3 \\
\hline $\begin{array}{l}\text { Nível primário - } \\
\text { Embalagem }\end{array}$ & $\begin{array}{l}\text { Nível secundário - } \\
\text { Embalagem }\end{array}$ & & & & & & & & & & & & & & & & & & & & \\
\hline $\begin{array}{l}\text { Informações sobre a } \\
\text { procedência }\end{array}$ & $\begin{array}{l}\text { Indicar o produtor } \\
\text { e sua relacăão com } \\
\text { instituiçōes }\end{array}$ & & & & & & 34,2 & 34,2 & 11,4 & & & & & & & & & 4 & 1 & 5,0 & 3,8 \\
\hline \multirow[t]{3}{*}{$\begin{array}{l}\text { Evidenciar a } \\
\text { responsabilidade } \\
\text { socioambiental }\end{array}$} & $\begin{array}{l}\text { Remeter à qualidade } \\
\text { de vida do produtor e } \\
\text { do consumidor }\end{array}$ & & & & & & 41,0 & 41,0 & 41,0 & & & & & & & & & 4 & 1,5 & 6,0 & 4,6 \\
\hline & $\begin{array}{l}\text { Indicar a produção } \\
\text { agroecológica }\end{array}$ & & & & & & 51,3 & 17,1 & 51,3 & & & & & & & & & 5 & 1,5 & 7,5 & 5,7 \\
\hline & $\begin{array}{l}\text { Apresentar } \\
\text { certificação orgânica } \\
\text { de acordo com as } \\
\text { normas brasileiras }\end{array}$ & & & & & & 48,7 & 0,0 & 48,7 & & & & & & & & & 4,75 & 1,5 & 7,1 & 5,4 \\
\hline $\begin{array}{l}\text { Possibilitar ver o } \\
\text { produto }\end{array}$ & Ser de vidro & & & & & & & & & 20,5 & & & & & & & & 3 & 1 & 3,0 & 2,3 \\
\hline \multirow[t]{4}{*}{$\begin{array}{l}\text { Permitir o } \\
\text { reaproveitamento }\end{array}$} & $\begin{array}{l}\text { Ser utilizada após o } \\
\text { consumo }\end{array}$ & & & & & & & & & 29,1 & & & & & & & & 4,25 & 1 & 4,3 & 3,2 \\
\hline & Possuir refil & & & & & & & & & 25,6 & & & & & & & & 3,75 & 1 & 3,8 & 2,8 \\
\hline & $\begin{array}{l}\text { Ter tampa adequada à } \\
\text { reutilização }\end{array}$ & & & & & & & & & 30,8 & & & & & & & & 4,5 & 1 & 4,5 & 3,4 \\
\hline & Ser reciclável & & & & & & & & & 0 & 34,2 & & & & & & & 5 & 1 & 5,0 & 3,8 \\
\hline \multirow[t]{3}{*}{ Tamanho adequado } & Ter de 250 a $300 \mathrm{~g}$ & & & & & & & & & 0 & 22,2 & & & & & & & 3,25 & 1 & 3,3 & 2,5 \\
\hline & Ter de 400 a $500 \mathrm{~g}$ & & & & & & & & & 0 & 5,7 & & & & & & & 2,5 & 1 & 2,5 & 1,9 \\
\hline & $\begin{array}{l}\text { Ter embalagens } \\
\text { pequenas (menores } \\
\text { de } 100 \mathrm{~g} \text { ) }\end{array}$ & & & & & & & & & & 3,4 & & & & & & & 1,5 & 1 & 1,5 & 1,1 \\
\hline \multirow[t]{6}{*}{$\begin{array}{l}\text { Aparência da } \\
\text { embalagem }\end{array}$} & $\begin{array}{l}\text { Ter rótulo de papel } \\
\text { reciclável }\end{array}$ & & & & & & & & & & 30,8 & 0,0 & 30,8 & 30,8 & 3,42 & & 4,5 & 1 & 4,5 & 3,4 & \\
\hline & $\begin{array}{l}\text { Ter rótulo impresso } \\
\text { na própria embalagem }\end{array}$ & & & & & & & & & & 0,0 & 20,5 & 20,5 & 20,5 & 2,2796 & & 3 & 1 & 3,0 & 2,3 & \\
\hline & Ter rótulo colorido & & & & & & & & & & 13,7 & 13,7 & 13,7 & 13,7 & 1,5198 & & 2 & 1 & 2,0 & 1,5 & \\
\hline & $\begin{array}{l}\text { Ter rótulo que remete } \\
\text { à natureza }\end{array}$ & & & & & & & & & & 6,3 & 6,3 & 6,3 & 18,8 & 0,0 & 0 & 2,75 & 1 & 2,8 & 2,1 & \\
\hline & Ter rótulo simples & & & & & & & & & & 29,1 & 9,7 & 9,7 & 3,2 & 3,2 & 0 & 4,25 & 1 & 4,3 & 3,2 & \\
\hline & Possuir uma marca & & & & & & & & & & 0,0 & 0,0 & 0,0 & 0,0 & 30,8 & 0 & 3 & 1,5 & 4,5 & 3,4 & \\
\hline Ser fácil de abrir & $\begin{array}{l}\text { Possuir sistema } \\
\text { especifico para } \\
\text { abertura }\end{array}$ & & & & & & & & & & & & & & & & 15,4 & 2,25 & 1 & 2,3 & 1,7 \\
\hline \multirow{4}{*}{  } & Peso absoluto & 92,7 & 131,0 & 53,6 & 81,6 & 155,9 & 275,3 & 198,8 & 100,0 & 106,0 & 65,5 & 79,8 & 50,2 & 80,9 & 87,0 & 41,2 & 15,4 & \multirow{4}{*}{$\begin{array}{l}1.767,3 \\
100 \%\end{array}$} & & 131,6 & 100,0 \\
\hline & Peso relativo & $5 \%$ & $7 \%$ & $3 \%$ & $5 \%$ & $9 \%$ & $16 \%$ & $11 \%$ & $6 \%$ & $6 \%$ & $4 \%$ & $5 \%$ & $3 \%$ & $5 \%$ & $5 \%$ & $2 \%$ & $1 \%$ & & & & \\
\hline & Qualidade projetada & $\operatorname{sim}$ & $\begin{array}{l}\text { aprox. } \\
40\end{array}$ & $\begin{array}{l}\text { de } 3 \\
\text { a } 3,2\end{array}$ & $\begin{array}{c}\text { de } 0,5 \\
\text { a } 1,5\end{array}$ & $\begin{array}{c}\text { de } \\
60 \mathrm{a} \\
67,5\end{array}$ & até 5 & $\operatorname{sim}$ & $\operatorname{sim}$ & $\operatorname{sim}$ & 300 & não & não & sim & $\operatorname{sim}$ & $\operatorname{sim}$ & não & & & & \\
\hline & Unidades/parâmetros & $\begin{array}{l}\text { sim/ } \\
\text { não }\end{array}$ & $\%$ & $\mathrm{pH}$ & $\%$ & $\%$ & $\%$ & sim/não & $\begin{array}{l}\operatorname{sim} / \\
\text { não }\end{array}$ & $\begin{array}{l}\text { sim/ } \\
\text { não }\end{array}$ & $\mathrm{g}$ & $\begin{array}{l}\operatorname{sim} / \\
\text { não }\end{array}$ & $\begin{array}{l}\operatorname{sim} / \\
\text { não }\end{array}$ & $\begin{array}{l}\operatorname{sim} / \\
\text { não }\end{array}$ & $\begin{array}{l}\operatorname{sim} / \\
\text { não }\end{array}$ & $\begin{array}{l}\operatorname{sim} / \\
\text { não }\end{array}$ & $\begin{array}{l}\operatorname{sim} / \\
\text { não }\end{array}$ & & & & \\
\hline
\end{tabular}


Produto \& Produção, vol. 14, n. 3, p. 19-34, out. 2013




de trituração e concentração (cocção) são as maiores responsáveis em atender às características da qualidade relacionadas à geleia. Dessa forma, é indicado para cada 10 litros de fruta 3 minutos de trituração e no processo de concentração (método de processamento em tacho aberto) o tempo de cozimento deve ser no máximo de 90 minutos, o teste da colher ou outro deve ser utilizado a fim de certificar o tempo adequado de cozimento.

Na Matriz 4 (Figura 6) foram relacionadas as matériasprimas e as características da qualidade. Observa-se que a fruta e o açúcar são os elementos com maior influência nas características da qualidade, seguidos da pectina e do ácido. Com relação à fruta o grau de maturação é primordial. No entanto, o tempo (dias) adequado para a fruta maturar varia de acordo com o tipo de fruta e das condições climáticas, como temperatura e chuva. Sendo assim, não é possível definir um tempo exato para essa etapa, cabendo ao agricultor definir com base no tipo de fruta e nas características climáticas de onde a mesma está sendo produzida. Portanto, não foi possível indicar unidades quando a característica da qualidade está relacionada com esse aspecto, como, por exemplo, na característica "ter pigmentos da fruta". Pelo mesmo motivo, os valores de controle também não foram indicados. O açúcar, a pectina e o ácido que irão compor a geleia devem ser orgânicos. $\mathrm{O}$ rótulo também é elemento relevante para atender às características da qualidade.

O modelo conceitual proposto leva em consideração aspectos apontados por Benner et al. (2003b) com relação ao desenvolvimento de produtos alimentares. $\mathrm{O}$ alimento é um produto sujeito às alterações dos atores da cadeia produtiva e das matérias-primas utilizadas. Dessa forma, o QFD é um método que possibilita determinar essas influências a fim de promover a determinação de metas e parâmetros de controle com o objetivo de garantir a qualidade do produto final exigida pelo cliente.

Cabe destacar que a equipe de desenvolvimento de produto que utiliza o método QFD deve ser multifuncional, abrangendo as funções de Marketing, Pesquisa e Desenvolvimento, Engenharia de Produto, Engenharia de Processo e Produção, conforme indicado por Cheng e Melo Filho (2007). Este trabalho consultou alguns especialistas durante as etapas de construção da proposta de aplicação. Entretanto, para que essa seja utilizada em uma empresa deverá ser formada uma equipe com representantes das diferentes funções a fim de garantir a eficácia do método.

Outra limitação importante é com relação à qualidade projetada. Os valores e parâmetros indicados não foram testados, pois o trabalho não foi desenvolvido em uma empresa e não teve acesso a uma para realizar os testes necessários. Portanto, os valores apresentados são referências que devem ser revistos quando da aplicação efetiva desta proposição no desenvolvimento de geleia de frutas orgânica.

Essa proposta difere da aplicação convencional do QFD, pois considera os atores da cadeia produtiva na primeira matriz, atribuindo também a esses a responsabilidade de atender às qualidades exigidas pelos clientes. Além disso, essa aplicação ocupou-se de um tipo de alimento diferente, os orgânicos, os quais possuem características que vão além daquelas tradicionalmente exigidas em alimentos, como por exemplo, a responsabilidade socioambiental. A substituição de valores-alvo por intervalos-alvo na qualidade projetada é outra diferença relevante na aplicação do método, pois os ingredientes são ainda materiais fisiologicamente ativos e, portanto, podem estar sujeitos a alterações.

\section{Conclusões}

O trabalho teve como objetivo propor uma aplicação do Desdobramento da Função Qualidade no desenvolvimento de produtos orgânicos. Para apresentação da referida proposta foi desenvolvida uma geleia de frutas orgânica. A proposta foi baseada em um modelo conceitual advindo da literatura, bem como em outros estudos os quais utilizaram o QFD no desenvolvimento de produtos alimentares. Porém, não foram encontrados trabalhos que utilizassem o QFD especificamente no desenvolvimento de produtos orgânicos.

Observou-se que a aplicação do QFD para desenvolver produtos alimentares carece de certas adaptações, tendo em vista que os ingredientes alimentares possuem variação natural na sua composição. Além disso, as muitas interações entre os ingredientes e a influência dos processos produtivos sobre as propriedades funcionais do produto e da cadeia produtiva sobre os ingredientes fazem com que o desenvolvimento de produtos alimentares tenha variáveis diferentes das de um produto não alimentar.

A modificação na primeira matriz, incluindo os integrantes da cadeia produtiva é fundamental para assegurar as qualidades exigidas pelo consumidor. Dessa forma, conclui-se que o método QFD necessita de adaptações para ser aplicado em produtos alimentares e que a inclusão da cadeia produtiva, bem como considerar as modificações que o alimento pode ter no processo produtivo e as suas variações naturais são pontos relevantes nessa adaptação. O modelo conceitual utilizado composto por quatro matrizes é fundamental para atender às qualidades exigidas, pois a cadeia produtiva, o processo produtivo e a matéria-prima demonstraram forte influência nas características da qualidade do produto final. É possível afirmar que o elemento da qualidade responsabilidade socioambiental é 
Produto \& Produção, vol. 14, n. 3, p. 19-34, out. 2013

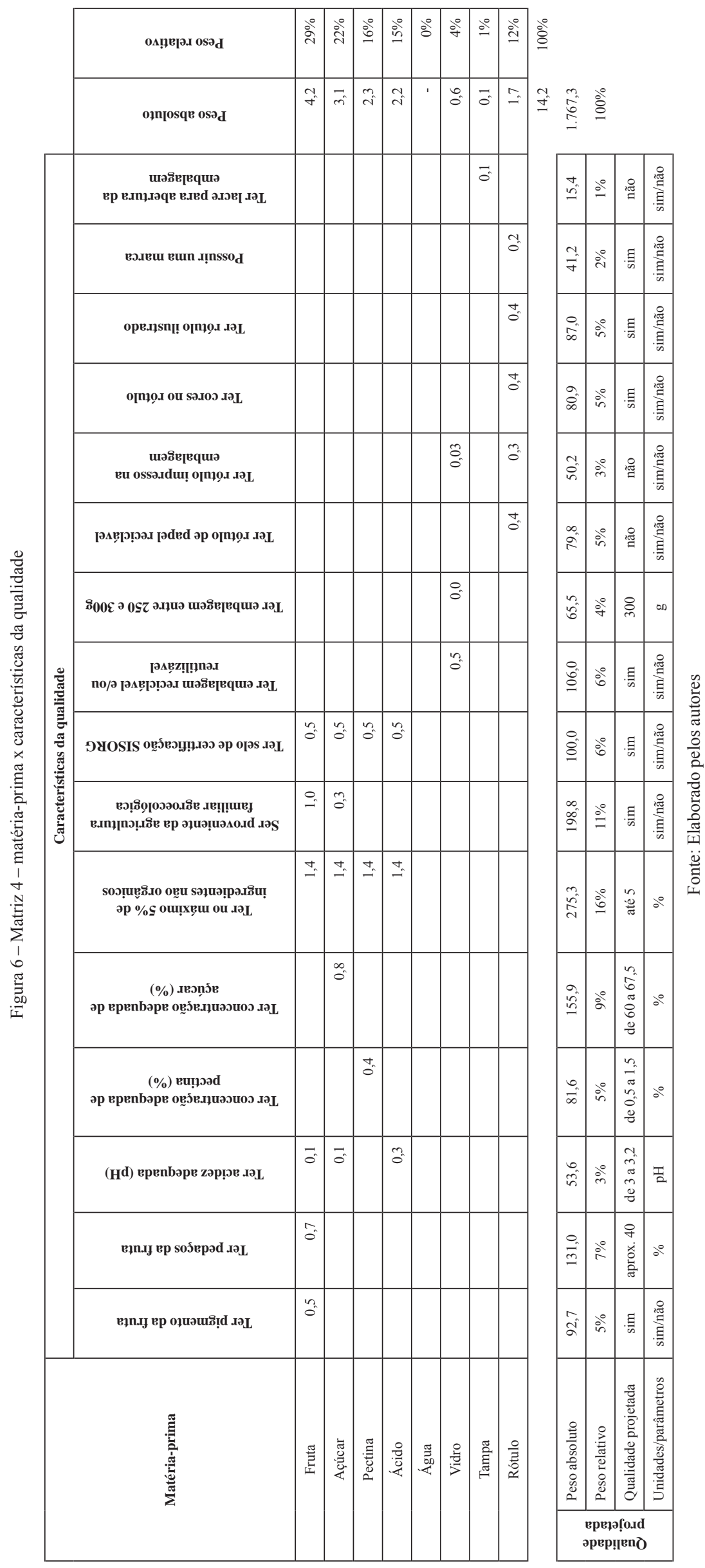


fundamental para desenvolver um produto orgânico, tal dimensão compreendeu $33 \%$ do peso relativo da qualidade projetada.

Cabe destacar que o consumo de alimentos orgânicos vem aumentando em todo o mundo, pois existem pessoas preocupadas com a sua saúde e com questões socioambientais. O alimento para ser orgânico deve atender a uma série de exigências conforme legislação específica, desde a semente ou muda da planta, passando pelo seu transporte e por outros ingredientes adicionados no processo de fabricação, até o processamento do produto final. Nesse sentido, o QFD pode auxiliar no relacionamento com o consumidor, identificando as qualidades exigidas de um produto orgânico, relacionando-as com a cadeia produtiva, extraindo as características da qualidade e fazendo as relações com o processo produtivo e a matéria-prima.

Embora este trabalho tenha consultado especialistas, para que essa proposta de aplicação do QFD seja utilizada em uma empresa, é sugerido que seja formada uma equipe multifuncional com representantes de diferentes áreas a fim de garantir a eficácia do método. Vale lembrar que os valores e parâmetros indicados não foram testados. Portanto, os valores aqui apresentados servem de referência quando da aplicação efetiva desta proposição no desenvolvimento de geleia de frutas orgânica. E isso consiste em uma indicação para futuros estudos.

Por fim, acredita-se que a aplicação proposta contribuiu para o método QFD no sentido de adaptá-lo para o desenvolvimento de produtos alimentares, mais especificamente os orgânicos. Ressalta-se ainda que o mercado desse tipo de produto encontra-se em crescimento. Frente a isso, é razoável que as empresas desenvolvam produtos a partir do ponto de vista do consumidor. Nesse sentido, o QFD vem ao encontro dessa necessidade pelo fato de sua aplicação traduzir a voz do cliente para o desenvolvimento do produto ainda na fase de projeto.

\section{Referências}

AKAO, Y. Quality Function Deployment: integrating customer requirements into product design. Cambridge, MA: Productivity Press, 1990.

AKAO, Y. Introdução ao desdobramento da qualidade. Belo Horizonte: Fundação Christiano Ottoni, 1996.

ARBOS, K. A. et al. Segurança alimentar de hortaliças orgânicas: aspectos sanitários e nutricionais. Ciência e Tecnologia de Alimentos, v. 30, n.1, p. 215-220, 2010.

BECH, A. C.; ENGELUND, E.; JUHL, H. J.; KRISTENSEN, K.; POULSEN, C. S. QFood-optimal design of food products. MAPP Working Paper No. 19, Aarhus, Denmark:University of Aarhus, 1994.

BENNER, M. et al. A chain information model for structured knowledge management: towards effective and efficient food product improvement. Trends in Food Science \& Technology, v. 14, n. 11, p. 469-477, 2003a.

BENNER, M. et al. Quality Function Deployment (QFD) - can it be used to develop food products? Food Quality and Preference, v. 14, n. 4, p. 327-339, 2003 b.

BENNER, M. The chain information model: A systematic approach for food product development. Doctoral dissertation. Wageningen, Netherlands: Wageningen University, 2005.

BENNER, M. et al. An explorative study on the systematic development of tomato ketchup with potential health benefits using the Chain Information Model. Trends in Food Science \& Technology, v. 18, n. 3, p. 150-158, 2007.

CARNEVAlli, J. A.; CAUCHICK MIGUEL, P. A. Revisão, análise e classificação da literatura sobre o QFD: tipos de pesquisa, dificuldades de uso e benefícios do método. Gestão \& Produção, v. 14, p. 557-579, 2007.

CARnEVAlli, J. A.; SASSI, A. C.; CAUCHICK MIGUEL, P. A. Aplicação do QFD no desenvolvimento de produtos: levantamento sobre seu uso e perspectivas para pesquisas futuras. Gestão \& Produção, v. 11, p. 33-49, 2004.

CARNEVAlLi, J. A.; CAUCHICK MIGUEL, P. A.; CALARGE, F. A. Proposta de um modelo conceitual para minimizar as dificuldades no uso do QFD. Produção, v. 18, p. 126-141, 2008.

CAUCHICK MIGUEL, P. A. Evidence of QFD best practices for product development: a multiple case study. International Journal of Quality \& Reliability Management, v. 22 n. 1, p. 72-82, 2005.

CHENG, L. C. QFD em desenvolvimento de produto: características metodológicas e um guia para intervenção. Produção Online, v. 3, n. 2, 2003.

CHENG, L. C; MELO FILHO, L.R. de. QFD: Desdobramento da função qualidade na gestão de desenvolvimento de produtos. São Paulo: Blücher, 2007.

DAROLT, M. R. As principais correntes do movimento orgânico e suas particularidades. In: DAROLT, M. R. Agricultura orgânica: inventando o futuro. Londrina: IAPAR, 2002. p. 18-26 (atualização realizada em 2010). 
DEVADASAN. D. et al. Theory and practice of total quality function deployment: A perspective from a traditional pump-manufacturing environment. The TQM Magazine, v. 18, n. 2, p. 143-161, 2006.

GUIVANT, J. S. Os supermercados na oferta de alimentos orgânicos: apelando ao estilo de vida ego-trip. Ambiente \& Sociedade, v. 6, n. 2, 2003.

HAUSER, J. R.; CLAUSING, D. The House of Quality. Harvard Business Review, v. 66, n. 5/6, p. 63-73, 1988.

HOFMEISTER, K. R. Quality Function Deployment: market success through customer driven products. In: GRAF, E.; SAGUY, I. S. (Eds.). Food product development: from concept to the market place. New York: Van Nostrand Reinhold, 1991. p. 189-210.

HOLMEN, E.; KRISTENSEN, P. S. Downstream and upstream extension of house of quality. MAPP Working Paper No. 19, Aarhus, Denmark: University of Aarhus, 1996.

KRISTIANTO, Y.; AJMAL, M. M.; SANDHU, M. Adopting TQM approach to achieve customer satisfaction: A flour milling company case study. TQM Journal, v. 24, n. 1, p. 29-46, 2012.

LAGER, T. The industrial usability of quality function deployment: a literature review and synthesis on a metalevel. R\&D Management, v. 35, n. 4, p. 409-426, 2005.

MIGUEL, A. C. A. et al. Aplicação do método QFD na avaliação do perfil do consumidor de abacaxi Pérola. Ciência e Agrotecnologia, v. 31, p. 563-569, 2007.
BRASIL. Ministério da Agricultura, Pecuária e Abastecimento. Secretaria de Desenvolvimento Agropecuário e Cooperativismo. Produtos orgânicos: o olho do consumidor. Brasília: MAPA/ACS, 2009.

PARK, S.-H.; HAM, S.; LEE, M.-A. How to improve the promotion of Korean beef barbecue, bulgogi, for international customers. An application of quality function deployment. Appetite, v. 59, n. 2, p. 324-332, 2012.

PINTO, A. L. D.; PAIVA, C. L. Desenvolvimento de uma massa funcional pronta para tortas utilizando o método de Desdobramento da Função Qualidade (QFD). Ciência e Tecnologia de Alimentos, v. 30, p. 36-43, 2010.

RIBEIRO, J. L.; ECHEVESTE, M. E.; DANILEVICZ, A. F. A Utilização do QFD na otimização de produtos, processos e serviços. Porto Alegre: FEENG, 2000.

ROSADO, A. G. et al. Identification of demand characteristics in the production of sires using a conceptual model of quality function deployment: a case study. Revista Brasileira de Zootecnia - Brazilian Journal of Animal Science, v. 40, n. 1, p. 210-220, jan. 2011.

SANTOS, G. C. dos; MONTEIRO, M. Sistema orgânico de produção de alimentos. Alimentos e Nutrição, v. 15, n. 1, p. 73-86, 2004.

WAISARAYUTT, C.; TUTIYAPAK, O. Application of quality function deployment in instant rice noodle product development. Kasetsart Journal - Natural Science, v. 40, n. suppl., p. 162-171, 2006.

Recebido em: 03/01/2013. Aceito em: 18/04/2013. 


\section{Apêndice - Utilização do QFD no desenvolvimento de produtos alimentares - detalhamento do Quadro 1}

\begin{tabular}{|c|c|c|c|}
\hline Referência & Objetivo & Aplicação do QFD & Resultados \\
\hline $\begin{array}{l}\text { Miguel et al. } \\
\text { (2007) }\end{array}$ & $\begin{array}{l}\text { Estabelecer o } \\
\text { comportamento de compra } \\
\text { dos consumidores de abacaxi } \\
\text { através do método QFD. }\end{array}$ & $\begin{array}{l}\text { Realizadas entrevistas individuais com } 85 \text { consumidores } \\
\text { no momento da compra. Definição do grau de importância } \\
\text { dos itens citados pelos consumidores. Definição da } \\
\text { qualidade planejada. Avaliação dos abacaxis por } 100 \\
\text { consumidores por meio de degustação (teste hedônico). }\end{array}$ & $\begin{array}{l}\text { O método QFD foi eficiente na avaliação do abacaxi. A } \\
\text { pesquisa e o teste hedônico revelaram que os consumidores } \\
\text { buscam frutas sem defeitos, de tamanho médio a grande, } \\
\text { maduras, firmes, suculentas, de boa aparência interna, que } \\
\text { sejam de coloração amarelada ou verde-amarelada, e que } \\
\text { apresentem aroma característico, baixa acidez e sabor doce. } \\
\text { Diante da insatisfação dos consumidores e considerando-se } \\
\text { que o abacaxi é consumido preferencialmente in natura, deve- } \\
\text { se atentar para a preservação da sua aparência e qualidade } \\
\text { sensorial. A opinião dos consumidores deve ser considerada } \\
\text { na tentativa de identificar os pontos que devem ser melhorados } \\
\text { dentro da cadeia de comercialização, a fim de reduzir as perdas } \\
\text { e promover a melhoria e a manutenção da qualidade do produto } \\
\text { final. }\end{array}$ \\
\hline $\begin{array}{l}\text { Pinto; Paiva } \\
\text { (2010) }\end{array}$ & $\begin{array}{l}\text { Desenvolver uma massa } \\
\text { alimentícia pronta para } \\
\text { o consumo com função } \\
\text { prebiótica. }\end{array}$ & $\begin{array}{l}\text { Realizadas entrevistas para avaliar as características que } \\
\text { os consumidores esperavam encontrar na massa, lugar e } \\
\text { circunstâncias em que gostariam de consumir o produto. } \\
\text { Construção da tabela de desdobramento das qualidades } \\
\text { exigidas. Extraída as características técnicas do produto } \\
\text { acabado. Conversão das qualidades exigidas em atributos } \\
\text { físico-químicos, microbiológicos e sensoriais do produto } \\
\text { acabado. Correlação entre as qualidades exigidas pelo } \\
\text { mercado e as características de qualidade do produto } \\
\text { acabado. O grau de importância das qualidades exigidas } \\
\text { foi estabelecido através de pesquisa com } 32 \text { possíveis } \\
\text { consumidores. Preparadas duas formulações de massas } \\
\text { de tortas, uma com maior quantidade de manteiga e outra } \\
\text { com menos gordura. Avaliação sensorial através do Teste } \\
\text { Afetivo de Aceitabilidade. Determinados os valores da } \\
\text { qualidade. Cálculo do índice de melhoria através da razão } \\
\text { entre os valores da qualidade planejada pelo desempenho } \\
\text { do produto na análise sensorial. Definida a qualidade } \\
\text { projetada, utilizando as especificações físico-químicas, } \\
\text { microbiológicas ou sensoriais para cada característica de } \\
\text { qualidade do produto acabado. Extraídas as características } \\
\text { de qualidade das matérias-primas. }\end{array}$ & $\begin{array}{l}\text { As qualidades exigidas mais importantes foram: ser funcional, } \\
\text { ser uma massa íntegra, ou seja, que não quebre, de sabor } \\
\text { neutro e com diâmetro e espessura uniformes. Em relação } \\
\text { às contribuições do método QFD para o desenvolvimento } \\
\text { do novo produto, destaca-se que a construção das matrizes } \\
\text { e as discussões inerentes a esta atividade proporcionaram } \\
\text { uma melhor percepção das relações entre as características } \\
\text { de qualidade do produto final es parâmetros de controle da } \\
\text { qualidade das matérias-primas. }\end{array}$ \\
\hline $\begin{array}{l}\text { Waisarayutt; } \\
\text { Tutiyapak } \\
\text { (2006) }\end{array}$ & $\begin{array}{l}\text { Analisar a consciência } \\
\text { atitude e valor para os } \\
\text { clientes-alvo de macarrão de } \\
\text { arroz instantâneo e avaliar } \\
\text { o potencial da utilização } \\
\text { de Desdobramento da } \\
\text { Função Qualidade (QFD) no } \\
\text { processo de desenvolvimento } \\
\text { de produto. }\end{array}$ & $\begin{array}{l}\text { Utilizado macarrão de arroz instantâneo de } 3 \text { empresas } \\
\text { líderes. Produto A selecionado para o estudo de caso a } \\
\text { fim de identificar as necessidades dos clientes. Produto } \\
\text { B e C usados para efetuar as comparações com o } \\
\text { produto A. Pesquisa com } 300 \text { consumidores. Utiliza a } \\
\text { Analisys of Cross Cultural Consumer Characterization } \\
\text { (4Cs). Realizada análise sensorial por um painel de } \\
\text { consumidores. Regressão linear foi utilizada para } \\
\text { correlacionar o modelo 4Cs e os fatores de qualidade do } \\
\text { produto. Elaborada a matriz de planejamento do produto } \\
\text { com base na performance da concorrência. Desenvolvida a } \\
\text { matriz de controle de processo. }\end{array}$ & $\begin{array}{l}\text { O método 4Cs apontou que a classe Reformador obteve uma } \\
\text { correlação com valor nutricional, sensorial e embalagem do } \\
\text { produto, enquanto o Mainstreamer teve uma correlação com } \\
\text { conveniência do produto e preço. A partir dos resultados de } \\
\text { análise de regressão linear, as diferentes qualidades exigidas } \\
\text { para o mesmo produto podem ser adotadas para comunicar } \\
\text { de acordo com o grupo de atitude de cliente identificado. } \\
\text { Dessa forma, a utilização desse método em conjunto com o } \\
\text { QFD possibilitou maior detalhamento das necessidades dos } \\
\text { diferentes tipos de clientes. }\end{array}$ \\
\hline $\begin{array}{l}\text { Kristianto; } \\
\text { Ajmal; Sandhu } \\
(2012)\end{array}$ & $\begin{array}{l}\text { Apresentar os resultados de } \\
\text { uma pesquisa de satisfação } \\
\text { do cliente levando em conta } \\
\text { a estratégia de gestão da } \\
\text { qualidade total (TQM), } \\
\text { aprovada em uma empresa de } \\
\text { moagem de farinha de trigo. }\end{array}$ & $\begin{array}{l}\text { Realizada pesquisa de satisfação de clientes com } 150 \\
\text { consumidores (realizada em } 2006 \text { e repetida em 2008), } \\
\text { a fim de levantar a qualidade requerida. Avaliado o } \\
\text { desempenho de dois concorrentes um nacional e um } \\
\text { internacional, } 200 \text { questionários distribuídos a clientes. } \\
\text { Definição das características da qualidade. Elaboração da } \\
\text { matriz de produção estratégica. Desenvolvimento de um } \\
\text { plano de ação, o qual será utilizado para avaliar a eficácia } \\
\text { do QFD. Elaboração da aferição técnica. }\end{array}$ & $\begin{array}{l}\text { QFD foi utilizado para medir a eficácia da gestão da qualidade } \\
\text { total, em um estudo comparativo realizado em dois momentos } \\
2006 \text { e } 2008 \text {. O método deve ser aplicado nos níveis mais } \\
\text { baixos de operações. Quando isso é aplicado, ele deve } \\
\text { incentivar as pessoas a aplicar o programa de melhoria de } \\
\text { qualidade de forma mais proativa. Isto encurta o ciclo de } \\
\text { vida de análise entre um QFD e outro e a empresa se torna } \\
\text { mais competitiva devido ao aumento da velocidade de suas } \\
\text { inovações. }\end{array}$ \\
\hline $\begin{array}{l}\text { Park; Ham; } \\
\text { Lee (2012) }\end{array}$ & $\begin{array}{l}\text { Utilizar o QFD para } \\
\text { identificar as necessidades } \\
\text { dos clientes norte- } \\
\text { americanos para o bulgogi, } \\
\text { um prato popular coreano. }\end{array}$ & $\begin{array}{l}\text { Utilização QFD das } 4 \text { fases. Realizadas duas pesquisas: } \\
\text { uma com clientes ( } 200 \text { clientes frequentadores de } \\
\text { restaurantes koreanos instalados em Manhattam) e } \\
\text { outra com } 20 \text { especialistas. Fase 1: matriz da qualidade } \\
\text { (qualidades exigidas x características da qualidade). } \\
\text { Fase 2: matriz características de engenharia e matriz } \\
\text { de correlação. Fase } 3 \text { : matriz de relacionamento entre } \\
\text { requisitos do cliente e características de engenharia. Fase } \\
\text { 4: matriz técnica - estabelecer a importância absoluta e } \\
\text { relativa de cada característica de engenharia. Foco na } \\
\text { primeira matriz. }\end{array}$ & $\begin{array}{l}\text { E empregou o QFD como ferramenta para melhoria do } \\
\text { produto, e centrou-se na primeira matriz (HOQ). Embora } \\
\text { a HOQ forneça as medidas técnicas de planejamento de } \\
\text { produtos, transformando as necessidades do cliente em } \\
\text { características de qualidade, essas informações devem seguir } \\
\text { em cascata para as próximas fases, tais como atividades de } \\
\text { design de produtos, etapas de planejamento do processo, ou } \\
\text { etapas de comercialização. O modelo das quatro fases, implica } \\
\text { aplicações repetidas de HOQ, nas fases de planejamento de } \\
\text { produto e de planejamento da produção, e dessa forma, poderia } \\
\text { sugerir métodos mais sistemáticos para aumentar o consumo } \\
\text { bulgogi no mercado internacional. }\end{array}$ \\
\hline
\end{tabular}


Continuação

\begin{tabular}{|c|c|c|c|}
\hline Referência & Objetivo & Aplicação do QFD & Resultados \\
\hline Rosado (2011) & $\begin{array}{l}\text { Determinar as principais } \\
\text { características de qualidade } \\
\text { exigidas pelos compradores } \\
\text { de touros em termos } \\
\text { de produtos e serviços } \\
\text { associados utilizando o } \\
\text { método de desdobramento da } \\
\text { função qualidade. }\end{array}$ & $\begin{array}{l}\text { Aplicação do QFD considerando produtos e serviços } \\
\text { juntos - modelo proposto por Ribeiro; Echeveste; } \\
\text { Danilevicz (2000). Primeira fase pesquisa qualitativa, } \\
\text { aplicado questionário, com } 9 \text { questões discursivas a um } \\
\text { grupo selecionado, utilizando amostra de conveniência } \\
\text { composta por } 5 \text { pessoas: professores universitários, } \\
\text { produtores e profissionais com experiência e que } \\
\text { trabalhavam no Rio Grande do Sul. As respostas foram } \\
\text { organizadas hierarquicamente, gerando uma árvore com } \\
\text { níveis primário, secundário e terciário. Tais informações } \\
\text { foram utilizadas para desenvolver um questionário } \\
\text { quantitativo, aplicado em } 58 \text { consumidores da empresa } \\
\text { estudada, a fim de identificar a ordem de importância das } \\
\text { características exigidas dos touros e dos serviços de valor } \\
\text { agregado. }\end{array}$ & $\begin{array}{l}\text { A adaptação do QFD para análise combinada (produto e } \\
\text { serviço) interfere nos resultados, particularmente aqueles } \\
\text { relacionados à priorização de serviços, e pode ser usado para } \\
\text { outros estudos sobre este produto. Os resultados evidenciaram } \\
\text { que os clientes priorizam as características relacionadas ao } \\
\text { produto, especialmente o valor genético dos touros. Os itens } \\
\text { de serviços também se destacaram, podendo configurar-se } \\
\text { como uma oportunidade de diferenciação entre as empresas } \\
\text { fornecedoras. }\end{array}$ \\
\hline
\end{tabular}

Fonte: Elaborado pelos autores com base na busca e análise da literatura 